\title{
Disc oedema in congenital amaurosis of Leber
}

\author{
JOHN T. FLYNN AND ROBERT F. CULLEN \\ From the Bascom Palmer Eye Institute, Departments of Ophthalmology and Neurology \\ University of Miami School of Medicine, Miami, Florida 33 г 36
}

Since it was first described by Theodor Leber as 'pigmentary retinitis with congenital amaurosis' (Leber, I 867), the entity which bears his name has been the subject of sporadic reports defining its clinical and pathological characteristics. It accounted for about ro per cent of the blindness in Sweden (Alstrom and Olsen, 1957) and i8 per cent among children in a series in Holland (SchappertKimmijser, Henkes, and van den Bosch, I959). The former report established its recessive inheritance pattern, first suspected by Leber, while the latter spelled out in detail its clinical findings. Other synonyms by which it is known reflect various concepts of its pathogenesis (Sorsby and Williams, I960; Waardenburg, 1957) -for example, retinal aplasia or neuroepithelial dysgenesis. Pathological material has been scant and varied. Sorsby's case (Sorsby and Williams, 1960) showed atrophy of all retinal layers. Other authors (Aubineau, 1903; Vrabec, I95I; Babel, I 963; Gillespie, I966; Horsten and Winkelman, 1960) found the neuroepithelium to be markedly affected with the rods and cones barely recognizable and the pigment epithelium proliferated. Kroll and Kuwabara (r964), in an electron microscopic study of a case, found an absence of rods, cones devoid of outer segments with short inner segments, and a few abnormal mitochondria. The pigment epithelium itself was reduced in height and contained large, round, irregular inclusion bodies. The various ophthalmological findings have been reviewed in detail (Dekaban and Carr, 1964; Krill, 1968; Karel, Brachfield, Styblová, and Sedláčhouá, 1967; Edwards, Price, and McDonald, I97I). Infants may be blind or nearly blind with a remarkably normal fundus appearance. Often pale discs, attenuated retinal vessels, and a fine 'pepper-and-salt' granularity of the pigment epithelium are noted. As the child grows older retinitis pigmentosa-like changes

This study was supported in part by the Harper Sibley, Jr, RLF Fund

Address for reprints: John T. Flynn, MD, $1638 \mathrm{NW}$ roth Avenue, Miami, Florida 33136 are said to occur. Pendular nystagmus, strabismus, sluggish pupils, and photophobia have frequently been observed. Two serious anterior segment abnormalities have also been noted in a significant number of these cases-cataracts and keratoconus (Schappert-Kimmijser and others, 1959; Karel, I968). These, however, usually occur in the teenage years and later. Electrophysiological testing methods, advocated as early as 1954 by Franceschetti and Dieterle (1957), have been employed prognostically. The association of congenital amaurosis with neurological dysfunction has been the subject of a number of reports (Sorsby and Williams, I960; Dekaban and Carr, I964; Krill, I 968; Karel and others, 1967; Henkes and Verduin, 1963), the most common associations being marked mental and motor retardation, epilepsy, hydrocephalus, hyper- and hypotonia, deaf-mutism, and hypo- and hyper-reflexia.

The purpose of this paper is to present two patients with anomalous disc oedema as an unusual manifestation of congenital amaurosis of Leber. In one the results of fluorescein angiography are given. The findings in four other patients with this diagnosis, who share, in our experience, the more typical manifestations of the syndrome as seen in infancy and early childhood, are also reported.

\section{Case reports}

CASE I

This white baby boy was first seen in May 1971 when aged 19 months. He had a history of poor vision and nystagmus which had been noted since he was 2-3 months old. His mother became aware of the occurrence of digito-ocular stimulation at about the age of 6-8 months. Growth and development were otherwise normal. His parents were not related to each other. Pregnancy and delivery were normal; his mother had had one previous spontaneous abortion. There was no family history of serious eye or central nervous system abnormalities on either side of the family.

\section{Examination}

The eyes were deep-set, the child was thought to have 
only perception of light in each eye. He seemed photophobic in bright light. A large-amplitude, low-frequency, random-directional nystagmus was present. No optically elicited or pursuit movements were found. The pupils measured $4 \mathrm{~mm}$ and reacted sluggishly to light. No evidence of cataract or keratoconus was apparent on anterior segment examination. Indirect ophthalmoscopy showed albinotic fundi. The discs appeared to be small and raised and the physiological cups were absent-an appearance suggesting oedema (Fig. I). The retinal veins were full, although the arteries appeared to be attenuated. No venous pulsations were present. There was no small vessel dilatation, nor were there aneurysms or haemorrhages on either of the discs. Retinal striae or folds about the disc were absent. The pigment epithelium appeared to be deranged in a pepper-and-salt fashion throughout the fundus, particularly in the macular region. Fluorescein angiography (Fig. 2) showed a diffuse disturbance of the retinal pigment epithelium. Early choroidal fluorescence was particularly striking in the macular region. The fluorescein angiographical findings of the discs were distinctive. In the early venous phase (Fig. 3a) hyperfluorescence could be seen beyond the sclero-choroidal ring and in the zone of retinal oedema. In the later venous phase (Fig. $3 b$ ), there was considerable leakage of dye into the disc and surrounding retinal tissues. This leakage continued and stained the disc and surrounding retina intensely in later pictures (Figs $3 c$ and $3 d$ show the disc of the left eye at a late stage). Retinoscopy disclosed a hypermetropic error of +8.00 dioptres in each eye. The electroretinogram was nonrecordable in both eyes (Fig. 4). A complete neurological examination and $x$-ray films of the skull and optic foramen were normal.

\section{Progress}

The child was followed-up during the next $3 \frac{1}{2}$ years without progression of the appearance of the disc or the retinal pigment epithelial changes. When 4 years old he was enrolled in a school for the visually handicapped, in which he did very well. The family moved from the area when the child was 5 years.

CASE 2

This white baby girl was seen in February 1973 at the age of 12 months. Pregnancy was normal; birth was slightly premature. Birth weight was $2.4 \mathrm{II} \mathrm{kg}$. There was no consanguinity of the parents and no family history of eye or nervous system defects could be elicited except that a maternal first cousin had strabismus. The parents questioned their baby's ability to see when aged 5 months and she was noted to have nystagmus at about that time.

\section{Examination}

The globes were not particularly deep-set in the orbit A pendular nystagmus with a quiet phase (Kestenbaum, 1961) in gaze up and left was present. She used a head turn to the right with chin depressed to obtain this gaze. Fixation (within the limits permitted by the nystagmus) and following movements could be elicited in both eyes.

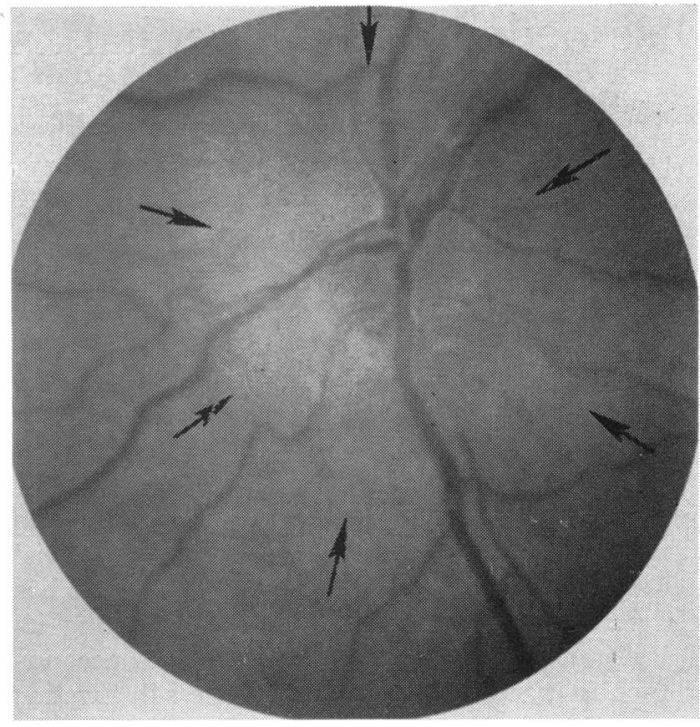

FIG. I (Case I) Optic disc of right eye. Arrows show extent of elevation. Disc is small, veins full, arteries narrow. No capillary dilatation or beading

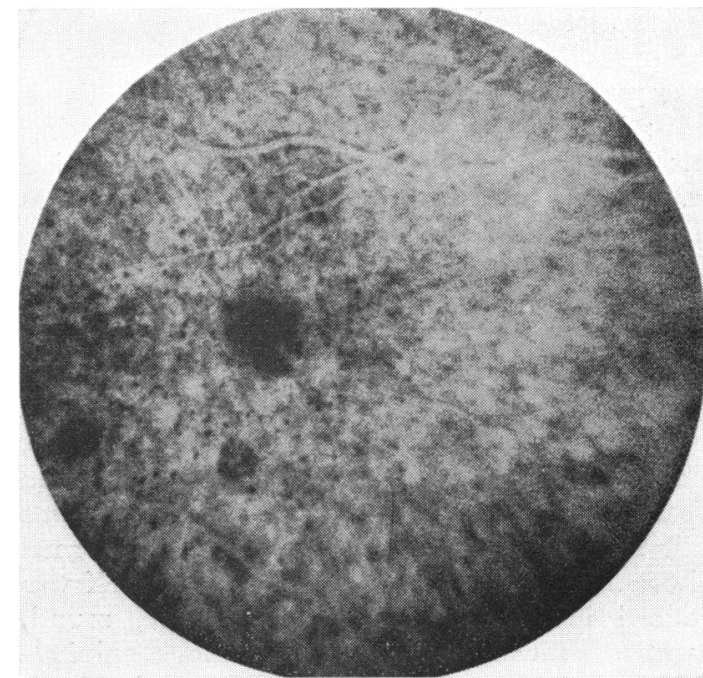

FIG. 2 (Case I) Fluorescein angiogram of right eye macular region, arterio-venous phase, showing diffuse disturbance of retinal pigment epithelium with choroidal fluorescence clearly seen

There was no latent component to the nystagmus noted The patient gave a definite positive response to vertical optokinetic testing. The pupils were of normal size and responded briskly to light directly and consensually. No photophobia or digito-ocular stimulation were noted. The anterior segments were completely normal. The dilated fundus examination revealed albinotic fundi. The discs appeared to be markedly raised(Fig. $5 a$ and $5 b$ ). The retina 


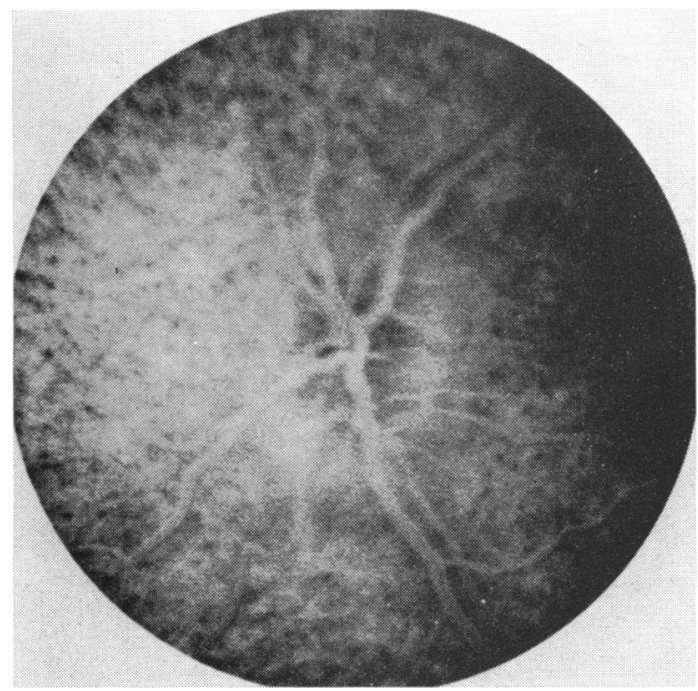

FIG. $3 a$ Fluorescein angiogram of the optic disc of right eye in early arterio-venous phase, demonstrating hyperfluorescence extending beyond the disc margin

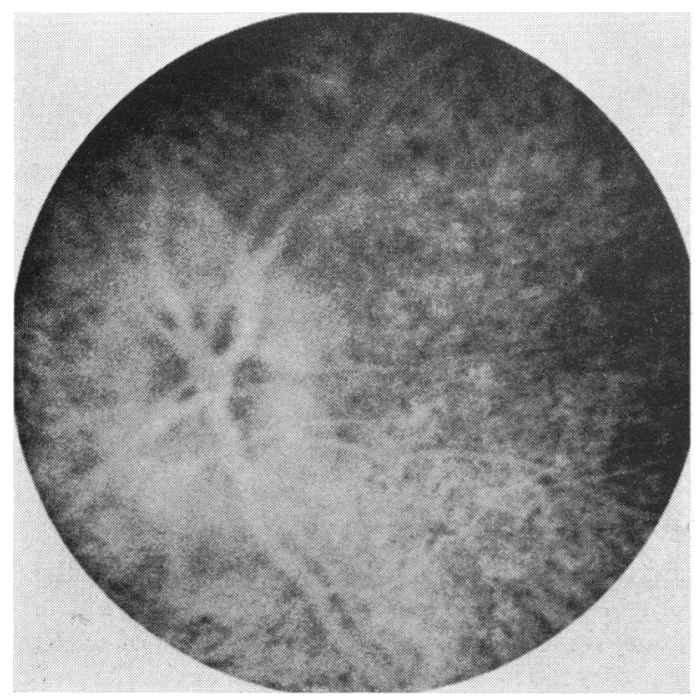

FIG. $3^{b}$ Late venous phase of fluorescein angiogram of optic disc of right eye, showing further leakage of dye with staining of disc and surrounding retina

and vessels leaving the disc appeared to be draped over this very swollen structure. The veins were full without pulsation. The arteries were normal in calibre. No small vessel dilatation, splinter haemorrhages, or striae were noted. There was a diffuse disturbance of the pigment epithelium throughout the fundus of each eye. Retinoscopy was +8.00 dioptres in the right eye and +6.50 dioptres in the left eye. The electroretinogram was extinguished. Neurological examination, and $x$-ray films of the skull and optic foramen were normal.

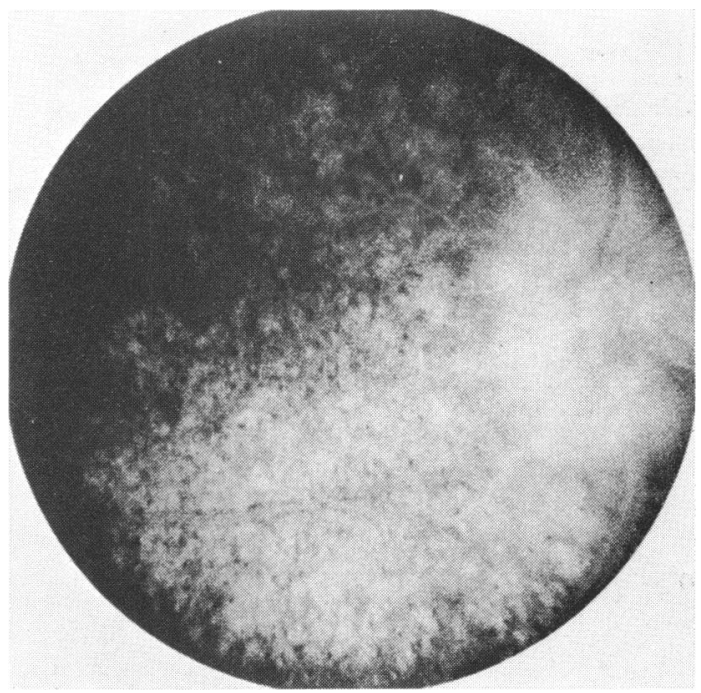

FIG. $3 c$ Still later phase of fluorescein angiogram of left eye. Disc and surrounding retina shows intense staining with fluorescein

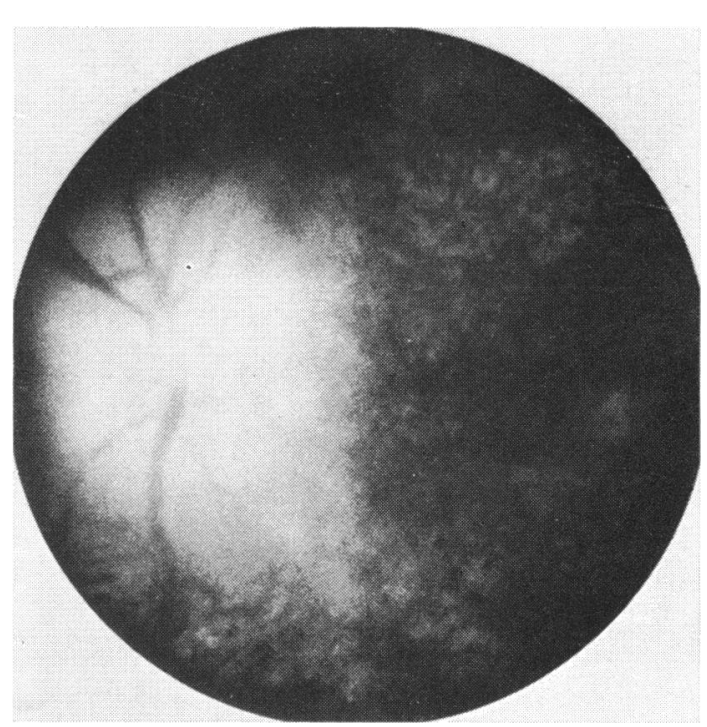

FIG. $3 d$ Disc and retinal fuorescence persisting in the left eye at a late stage

The family moved from the area one month later and no further follow-up was possible.

\section{Further clinical cases}

We have followed-up a total of four cases in addition to those presented above (Table). They have all shown the more typical findings of a pale disc, attenuated vessels, and a marked, diffuse 

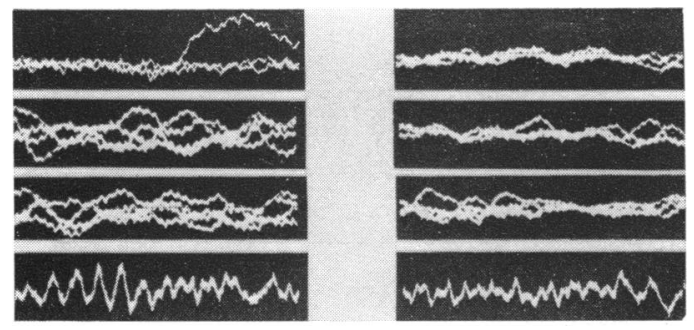

FIG. 4 (Case I) Extinguished electroretinography. Scotopic : upper 3 traces; photopic (flicker) : lower trace

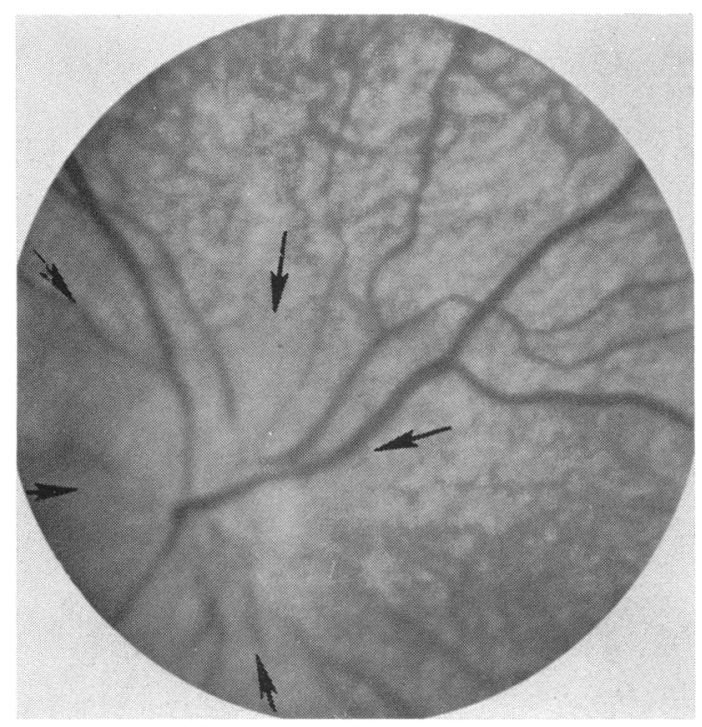

(5a)

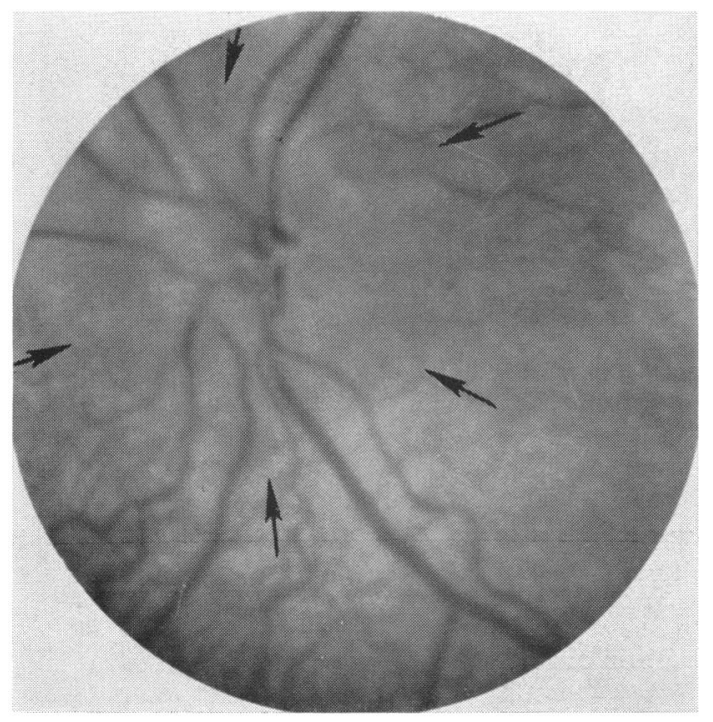

(5b)

FIG. 5a and b (Case 2) Optic discs to show extent of the raised area of disc in each eye

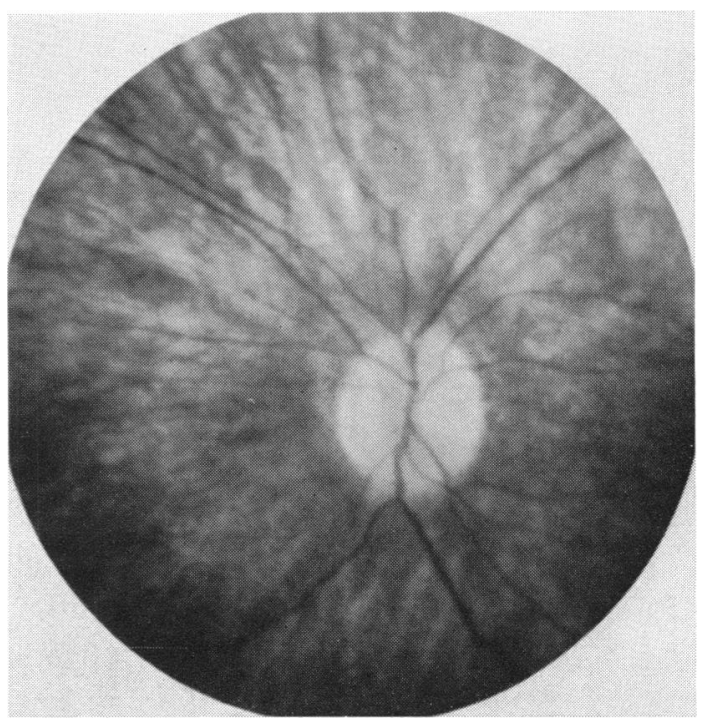

FIG. 6 'Typical' appearance of fundus in 7-year-old child with Leber's congenital amaurosis (Case 5). Disc pallor, attenuated vessels and diffuse pigment epithelial abnormality

retinal pigment epithelial abnormality (Fig. 6) and a non-recordable electroretinogram. The best visual acuity in the group was $20 / 70$. None was an extreme hypermetrope, as were the two patients detailed above. Two were mentally retarded, and one had multiple congenital anomalies including atrial septal defect, poly- and syndactyly of the fingers and toes, and bladder diverticulum. One had hypoactive and one hyperactive deep tendon reflexes. Their complete neurological findings will be the subject of another report.

\section{Comment}

The two patients presented in detail add another finding-disc oedema to the impressive list of various signs that congenital amaurosis of Leber can present. Its occurrence in this entity has not been stressed before, although Schappert-Kimmijser and others (1959) did mention a 'papillitis' appearance of the disc in their report on children with congenital amaurosis without further elaboration.

The aetiology of the disc swelling in both our patients and the explanation of the fluorescein angiogram in the first patient are obscure. High hypermetropia with a small eye could give rise to a crowded appearance of the optic disc, the so-called 'pseudoneuritis'. However, such a disc does not leak fluorescein into surrounding retinal tissues (Haining, 1966). The occurrence of profound loss of vision coupled with this disc appearance in an 
Table Additional cases of amaurosis congenita showing more typical manifestations

\begin{tabular}{|c|c|c|c|c|c|c|c|c|c|c|c|c|c|}
\hline Patient & $\begin{array}{l}\text { Age } \\
\text { (yrs) }\end{array}$ & $\begin{array}{l}\text { Family } \\
\text { history }\end{array}$ & Vision & Nystagmus & Strabismus & Pupils & $\begin{array}{l}\text { Electro- } \\
\text { retino- } \\
\text { gram }\end{array}$ & $\begin{array}{l}\text { Optic } \\
\text { discs }\end{array}$ & $\begin{array}{l}\text { Retinal } \\
\text { vessels }\end{array}$ & $\begin{array}{l}\text { Pigment } \\
\text { epithelium }\end{array}$ & $\begin{array}{l}\text { Neuro- } \\
\text { logical }\end{array}$ & $\begin{array}{l}\text { Electro- } \\
\text { encephalc- } \\
\text { gram }\end{array}$ & - Other \\
\hline 3 & 4 & - & $\begin{array}{l}\text { Light } \\
\text { perception } \\
\text { both eyes }\end{array}$ & $\stackrel{+}{\text { Pendular }}$ & $\mathrm{E}^{+} \mathrm{T}^{* * *}$ & Sluggish & Absent & $\begin{array}{l}+++ \\
\text { Pale }\end{array}$ & $\begin{array}{l}+++ \\
\text { Attenuated }\end{array}$ & $\begin{array}{l}\text { Diffuse } \\
\text { 'pepper- } \\
\text { and-salt' } \\
\text { change }\end{array}$ & Retarded & ND* & 0 \\
\hline 4 & 3 & $\begin{array}{l}\text { Sibling } \\
\text { with } \\
\text { epilepsy }\end{array}$ & $\begin{array}{l}\text { ? } \\
\text { Hand } \\
\text { move- } \\
\text { ments }\end{array}$ & $\begin{array}{l}+ \text { Jerk } \\
\text { horizontal } \\
\text { and } \\
\text { vertical }\end{array}$ & ET*** & Sluggish & Absent & $\stackrel{+}{\text { Pale }}$ & $\stackrel{+}{\text { Attenuated }}$ & $\begin{array}{l}\text { Mild } \\
\text { abnormal } \\
\text { albinotic } \\
\text { fundus }\end{array}$ & Normal & $\mathrm{ND}^{*}$ & $\circ$ \\
\hline 5 & 7 & $\begin{array}{l}\text { ? } \\
\text { Consan- } \\
\text { guinity }\end{array}$ & $10 / 200$ & $\stackrel{+}{\text { Pendular }}$ & ${ }_{\text {E'T*** }}^{+*}$ & Sluggish & Absent & $\stackrel{+}{\text { Pale }}$ & $\begin{array}{l}++ \\
\text { Attenuated }\end{array}$ & $\begin{array}{l}\text { Diffuse } \\
\text { 'pepper- } \\
\text { and-salt' } \\
\text { change }\end{array}$ & Retarded & $\mathrm{ND}^{*}$ & $t^{* *}$ \\
\hline
\end{tabular}

* ND $=$ Not done

** Patient had syn- and polydactyly, congenital heart disease, bladder diverticulum

*** ET $=$ Esotropia

infant or child might make one suspicious of an inflammatory swelling of the optic nerve head. However, the type of swelling caused by papillitis gives rise to a picture of radially arranged engorged capillaries connected by vascular bridges that are spread over the disc and especially prominent in chronic inflammatory processes involving the disc (Wessing, 1968). True papilloedema shows early and extensive dilatation of the disc capillaries as well as dye extravasation as distinguishing angiographical signs (Blair and Walsh, 1969). This dilatation was not seen in our patients nor was the neurological picture in either of them suggestive of a space-occupying intracranial mass. The fluorescein picture resembled, to a certain extent, the 'ischaemic oedema' described by Karel, Otradovec, and Peleska (1972) as occurring with drusen of the optic disc. The clinical picture in all their patients, however, was one of sudden loss of vision occurring in adult patients accompanied by oedema of the disc, capillary dilatation, and later the development of optic atrophy. Witmer ( 1967 ) described ischaemic oedema of the optic disc without capillary dilatation, and we feel that the disc oedema in our patients represents some form of stasis oedema akin to this. We cannot exclude the possibility that the unusual appearance of the optic nerve head in both these patients was due to deep-lying drusen of the optic disc in small hyperopic eyes causing some local haemodynamic changes resulting in oedema.

A further essential point is the awareness that this disc appearance can occur in association with Leber's amaurosis. Such a patient will frequently present as a blind, retarded child with nystagmus. The picture of the disc, so suggestive of papilloedema, may cause confusion and lead to further neurological studies which are unnecessary to elucidate the cause of the blindness. The finding of an extinguished electroretinogram is confirmatory of the presence of Leber's amaurosis. Of interest, also, is the occurrence of high hypermetropia in association with both our cases. Karel and others (1967) and Karel (1968) have drawn attention to the association of high hypermetropia with cataracts and keratoconus in their group of patients with Leber's amaurosis. It is possible to speculate that the disc elevation, the keratoconus, and the cataract are manifestations of a structural abnormality of the entire globe itself. Unfortunately, ultrasonography was not available at the time when these patients were under our observation.

We acknowledge our gratitude to Richard Lewis, MD, for considerable help in the interpretation of the fluorescein angiograms.

\section{References}

ALSTROM, C. H., and OLSEN, O. (1957) Hereditas (Lund), 43, I

aubineau, M. (1903) Ann. Oculist. (Paris), 129, 432

BABEL, J. (1963) Ophthalmologica (Basel), 145, 399

Bl.air, C. J., and Walsh, F. B. (1969) Trans. Amer. Acad. Ophthal. Otolaryng., 73, 914 
Dekaban, A., and CARr, R. (1964) Arch. Neurol. (Chic.) 14, 294

EDWARDS, W. C., PRICE, W. D., and MCDONALD, R. JR. (I97I) Amer. F. Ophthal., 72, 724

FRANCESCHETTI, A., and DIETERLE, P. (1957) Bibl. ophthal. (Basel), 48, I6I

Gillespie, f. (1966) Amer. $\mathcal{F}$. Ophthal., 6r, 874

haINING, w. M. (I966) Brit. F. Ophthal., 50, 587

HENKES, H. E., and VERDUIN, P. C. (1963) Ophthalmologica (Basel), 145, 144

HORSTEN, G. P. M., and Winkelman, J. E. (1960) Arch. Ophthal., 63, 232

KAREL, I. (1968) Ophthalmologica (Basel), 155, 8

- BRAChField, K., STYBlová, v., and SEDláČHouá, E. (1967) 'Progress in Neuro-Ophthalmology', ed. J. R.

Brunette and A. Barbeau, vol 2, p. 377. Excerpta Medica, Amsterdam

- OTRADOVEC, J., and PELESKA, M. (1972) Ophthalmologica (Basel), 164, 449

Kestenbaum, A. (1961) 'Clinical Methods of Neuro-Ophthalmological Examination', p. 335. Grune \& Stratton,

New York

KRILL, A. E. (1968) 'Symposium on Surgical and Medical Management of Congenital Anomalies of the Eye'. Trans-

actions of New Orleans Academy of Ophthalmology, p. 447. Mosby, St Louis

Kroll, A., and KuWABARA, T. (1964) Arch. Ophthal., 71, 683

LEBER, T. (1867) v. Graefes Arch. Ophthal., 15, I

SCHAPPERT-KIMMIJSER, J., HENKES, H. E., and VAN DEN BOSCH, J. (1959) Arch. Ophthal., 6r, 2 I I

SORSBY, A., and WIlliams, C. E. (1960) Brit. med. F., 1, 293

VRABEC, F. (195I) Ophthalmologica (Basel), 122, 65

WAARDENBURG, P. J. (1957) Ibid., 133, 454

WEssing, A. (1968) 'Fluorescein Angiography of the Retina: Textbook and Atlas', p. I 73, trans by G. K. von Noorden.

Mosby, St Louis

WITMER, R. (1967) Docum. ophthal. (Den Haag), 26, 359 